\title{
The role of testosterone in type 2 diabetes and metabolic syndrome in men
}

\author{
O papel da testosterona no diabetes melito tipo 2 \\ e síndrome metabólica em homens
}

Farid Saad ${ }^{1}$

\begin{abstract}
Over the last three decades, it has become apparent that testosterone plays a significant role in glucose homeostasis and lipid metabolism. The metabolic syndrome is a clustering of risk factors predisposing to diabetes mellitus type 2, atherosclerosis and cardiovascular morbidity and mortality. The main components of the syndrome are visceral obesity, insulin resistance, glucose intolerance, raised blood pressure and dyslipidemia (elevated triglycerides, low levels of high-density lipoprotein cholesterol), and a pro-inflammatory and thrombogenic state. Crosssectional epidemiological studies have reported a direct correlation between plasma testosterone and insulin sensitivity, and low testosterone levels are associated with an increased risk of type 2 diabetes mellitus, dramatically illustrated by androgen deprivation in men with prostate carcinoma. Lower total testosterone and sex hormone-binding globulin (SHBG) predict a higher incidence of the metabolic syndrome. There is evidence that hypotestosteronemia should be an element in the definition of the metabolic syndrome since low levels of testosterone are associated with or predict the development of the metabolic syndrome and of diabetes mellitus. Administration of testosterone to hypogonadal men reverses part of the unfavorable risk profile for the development of diabetes and atherosclerosis. So far, studies on the effects of normalization of testosterone in hypogonadal men on glucose homeostasis are limited, but convincing, and if diabetes mellitus is viewed in the context of the metabolic syndrome, the present results of testosterone treatment are very encouraging. Arq Bras Endocrinol Metab. 2009;53(8):901-7
\end{abstract}

Keywords

Testosterone; metabolic syndrome; cardiovascular risk factors; insulin sensitivity; diabetes mellitus

\section{RESUMO}

Ao longo das últimas três décadas, tornou-se evidente que a testosterona desempenha um papel significativo na homeostase da glicose no metabolismo lipídico. A síndrome metabólica é um agrupamento de fatores de risco que predispõem ao diabetes melito tipo 2, aterosclerose e morbidade e mortalidade cardiovasculares. Os principais componentes da síndrome são: obesidade visceral, resistência insulínica, intolerância à glicose, hipertensão arterial e dislipidemia (triglicerídeos elevados, baixos níveis de HDL-colesterol), além de um estado pró-inflamatório e trombogênico. Estudos epidemiológicos transversais relataram uma correlação direta entre testosterona plasmática e sensibilidade à insulina, e níveis baixos de testosterona se associam com risco aumentado de diabetes tipo 2, ilustrado dramaticamente pela privação androgênica em homens com carcinoma de próstata. Baixos níveis de testosterona total e globulina transportadora de hormônios sexuais (SHBG) predizem maior incidência de síndrome metabólica. Existem agora evidências de que a hipotestosteronemia deveria ser um elemento na definição da síndrome metabólica, uma vez que baixos níveis de testosterona estão associados ou predizem o desenvolvimento de síndrome metabólica e de diabetes melito. A administração de testosterona a homens hipogonádicos reverte parte do perfil desfavorável de risco para o desenvolvimento de diabetes e aterosclerose. Até agora, os estudos relacionados aos efeitos da normalização da testosterona em homens hipogonádicos sobre a homeostase da glicose são limitados, mas convincentes e, se o diabetes melito for visto no contexto da síndrome metabólica, os resultados atuais do tratamento com testosterona são muito encorajadores. Arq Bras Endocrinol Metab. 2009;53(8):901-7
1 Bayer Schering Pharma AG, Berlin, Germany and Gulf Medical University School of Medicine, Ajman, UAE
Correspondence to: Farid Saad

BU Primary Care/Men's Healthcare Scientific Affairs

c/o Bayer Schering Pharma AG,

D-13342 Berlin, Germany

Geb. S101, 09, 226

Farid.Saad@bayerhealthcare.com

Received on Aug/18/2009

Accepted on Oct/8/2009 


\section{INTRODUCTION}

$\mathrm{F}$ or the average clinician, testosterone is the hormone that subserves reproductive and sexual functioning. Further connotations of the hormone are that testosterone is an etiological factor in prostate cancer, presumed from the clinical experience that androgen ablation in eligible patients is a successful treatment method for prostate cancer. Additionally, testosterone is perceived as a risk factor for cardiovascular disease accounting for the significantly higher prevalence of coronary heart disease (CHD) in men as compared to women. Mortality from CHD is at least twice as high in men as it is in women. This is true in all areas of the world whether in a high incidence area (like in UK/ Scotland) or in a low incidence area like in Japan. This relationship persists at all ages, so that at any age coronary death rates are higher in men than in women. This sex difference has been attributed to the difference in profiles of circulating sex steroids, with testosterone as the most obvious difference between the sexes. Careful analysis has proven both assumptions wrong. Estrogens are not cardio-protective and there is no solid evidence that testosterone is a significant factor in the etiology of prostate cancer and of cardiovascular disease. But these traditional beliefs are deeply rooted and it will require thorough physician education before these beliefs are abandoned.

This contribution focuses on the role of testosterone in type 2 diabetes mellitus in men. It presents new data and insights of the role of testosterone in metabolic processes; mainly in elderly men derived from own recent publications and the literature available in PubMed. The conclusion is that elderly men with type 2 diabetes often have hypogonadal values of circulating testosterone and that clinical studies are being conducted to test whether normalization of circulating testosterone levels might contribute to the improvement of the metabolic control in men with diabetes type 2 and the wide array of its complications. The first results are in confirmation of this assumption. If an intervention with administration of testosterone would turn out to be successful in the management of diabetes mellitus type 2 in elderly men, this would be a revolutionary development in the traditional approach to its treatment. Physicians who treat men with diabetes are often not experienced in diagnosis and treatment of androgen deficiency. So, it will require substantial physician education to bring these new insights to their attention.
Until a decade ago, the ailments of elderly men, such as atherosclerosis, hypertension, diabetes mellitus, lower urinary tract symptoms and erectile dysfunction, were regarded as distinct diagnostic/therapeutic entities, but there is growing evidence that these entities are not disparate in their etiology and, to improve the overall health of the aging male, require an integral approach. There is an interdependence between the metabolic syndrome, diabetes mellitus type 2 , erectile dysfunction, and patterns of testosterone in aging men (1). With these recent insights, the health problems of elderly men must be placed in a clinical context that allows a more comprehensive and integral approach. Diagnosis and treatment of testosterone deficiency is to become part of that integral approach to the health problems of elderly men. It is obvious that testosterone treatment is not a cureall for elderly men. But for too long the relevance of testosterone for the pathophysiology of the aging male has been underestimated, if not dismissed. The only solid reason for testosterone treatment of elderly men is a proven testosterone deficiency, but the latter is not a rare occurrence in elderly men. Meanwhile several professional organizations have formulated guidelines for diagnosis and treatment of testosterone deficiency in elderly men, which help them to make responsible decisions.

\section{DIABETES MELLITUS TYPE 2 AND THE METABOLIC SYNDROME}

Most elderly men presenting with diabetes type 2 suffer from the metabolic syndrome. The metabolic syndrome is an insulin resistance syndrome with simultaneous occurrence of abdominal obesity, impaired fasting glucose, impaired glucose tolerance or overt type 2 diabetes, dyslipidemia and hypertension. Other medical disorders, such as erectile dysfunction and lower urinary tract symptoms, are also associated with this cluster of symptoms. Most important, the metabolic syndrome results in a severe increase of morbidity and mortality. The incidence of metabolic syndrome increases rapidly both in the western world, and even more in developing countries. Although the metabolic syndrome currently receives wide attention, it was described more than 80 years ago, and the significance of abdominal obesity was already noted 60 years ago.

Central or visceral obesity causes increased inflow of free fatty acids into the liver via portal venous drainage and induces metabolic disorders due to a perturbation of liver metabolism. Liver fat is highly, significantly and 
linearly correlated with all components of the metabolic syndrome. The question raised is whether nonalcoholic fatty liver disease should be included in the definition of metabolic syndrome. Hepatic steatosis or nonalcoholic fatty liver disease has gained attention as an important factor in the pathogenesis of insulin resistance and the metabolic syndrome. Peptides and cytokines secreted by adipocytes in the visceral compartment may cause a decrease in peripheral insulin mediated glucose uptake and may increase hepatic fat accumulation. Elevations of liver enzymes are associated with higher levels of C-reactive protein (CRP).

\section{TESTOSTERONE IN MEN SUFFERING FROM DIABETES MELLITUS}

Similarly to studies in men with the metabolic syndrome, there is an inverse relationship between testosterone levels and diabetes in this group of patients. Men with diabetes have lower testosterone levels compared to men without a history of diabetes $(2,3)$, and there is an inverse association between testosterone levels and glycosylated hemoglobin. This no artifact due to medication with, for instance, statins (3). A systematic review and meta-analysis of cross-sectional studies indicated that testosterone level was significantly lower in men with type 2 diabetes (mean difference, $-76.6 \mathrm{ng} /$ $\mathrm{dL} ; 95 \%$ confidence interval $[\mathrm{CI}],-99.4$ to -53.6$)$. In men with low plasma testosterone, the probability of diabetes mellitus is increased. Prospective studies have shown that men with higher testosterone levels (range, $449.6-605.2 \mathrm{ng} / \mathrm{dL}$ ) had a $42 \%$ lower risk of type 2 diabetes (RR, 0.58 ; 95\% CI, 0.39 to 0.87 ) (4). In addition, several large prospective studies have shown that low testosterone levels predict development of type 2 diabetes in men. There is persuasive epidemiological evidence from several longitudinal population studies that low testosterone is an independent risk factor for the development of both the metabolic syndrome and type 2 diabetes in later life $(2,5)$. The Massachusetts Male Aging Study (MMAS) and the Multiple Risk Factor Intervention Trial (MRFIT) have shown that low levels of total testosterone and SHBG (which is associated with insulin resistance) were both independent risk factors in middle-aged men who later developed diabetes. The Rancho-Bernardo Study based in California demonstrated a significant inverse correlation between baseline total testosterone with long-term ( 8 year follow-up) fasting glucose and insulin levels as well as glucose intolerance. A Finnish study has shown that low testosterone and SHBG levels also predict the development of the Metabolic Syndrome as well as diabetes. Importantly, the MMAS has provided evidence that low testosterone is a risk factor for metabolic syndrome and diabetes in men who were not initially obese. Recently, the Third National Health and Nutrition survey (NHANES III), in a population of 1,413 men after adjustment for age, race/ethnicity and adiposity, showed that those men initially in the lowest tertile of either free or bioavailable but not total testosterone were approximately four times more likely to have prevalent diabetes in comparison to those in the third tertile. These findings support those of the MMAS in that the risk does not depend on adiposity.

Interestingly, there is a significant difference in plasma testosterone levels between men with diabetes type 1 (who have normal levels) and type 2 (who have subnormal levels) (6). This difference was attributed to the differences in circulating levels of insulin (low in type 1 and high in type 2). There is an inverse relationship between insulin levels and sex hormone binding globulin (SHBG) and, consequently, plasma levels of total testosterone are lower in men with type 2 diabetes. This assumption is confirmed by the observation that men with type 1 diabetes with a high BMI show lower levels of testosterone. Androgen receptor CAG repeat polymorphism appears associated with serum testosterone levels, obesity and serum leptin in men with type 2 diabetes (7).

\section{DOES THE ADIPOSE TISSUE SUPPRESS THE SYNTHESIS OF TESTOSTERONE?}

While men with diabetes and/or the metabolic syndrome often have lower-than-normal testosterone levels, the question has arisen whether adipose tissue itself might depress synthesis of testosterone. In recent years, it has been demonstrated that the fat cell functions as an endocrine cell, producing and secreting molecules with regulatory potential, the so-called cytokines/adipokines of which leptin is a prominent member. Leptin may be a factor in the association between adiposity and decreased testosterone levels. In men, there seems to exist a correlation between body mass index and fat mass on the one hand and leptin levels on the other. Leptin receptors are present on the Leydig cell and inhibit the testosterone generated by administration of human chorionic gonadotropin. This may be a model 
for a less effective stimulation of testosterone production by luteinizing hormone when circulating leptin levels are high, as is the case of obesity. This finding was supported by studies that found a negative correlation between adiposity, insulin and leptin on the one hand and testosterone levels on the other. More studies have found that insulin is an important determinant of leptin levels. Feeding and overfeeding increase insulin levels which leads to an increase in leptin, and vice-versa.

Hyperinsulinemia, as encountered in insulin resistance, might impair testosterone secretion by the Leydig cell, maybe directly since there are insulin receptors on the Leydig cell (8).

It has also been found in obese men that there is an attenuated pulse amplitude of luteinizing hormone (LH) while the LH pulse frequency is unaffected, thus producing a less strong stimulation of testicular testosterone production. In morbidly obese men, altered glycosylation of $\mathrm{LH}$, with selective increase in the release of less acidic (biologically inactive) LH isoforms, with a decreased ratio of the biological to immunological ratio of LH, may represent an additional mechanism modulating the hypogonadal state prevailing in morbid obesity (9). This may explain why the nature of the hypogonadism associated with diabetes mellitus type 2 appears to be hypogonadotropic. Correlation studies cannot unravel the cause and effect relationships between the correlates whether low testosterone/low SHBG induces visceral fat deposition or whether a large visceral fat depot leads to low testosterone levels. In men with the metabolic syndrome, increases and decreases in body weight are associated with higher/lower insulin levels, with lower/higher SHBG levels and with lower/higher plasma testosterone. Obviously, weight loss will reduce the harmful effects of the metabolic syndrome.

\section{CAN THE AGE-RELATED DECLINE OF TESTOSTERONE BE PREVENTED OR REVERSED?}

As indicated above, the age-related changes in neuroendocrine functioning that lead to a diminished efficacy of LH stimulation of the Leydig cell and impairments of the steroidogenic process of testosterone synthesis are probably inherent factors in the age-related decline of circulating testosterone levels. One of the early studies concluded that aging is the main factor in this process. But increasingly there is insight that the disease significantly contributes to the age-related decline of testosterone (10). Numerous studies have found associations between features of the metabolic syndrome and plasma testosterone, and changes in lifestyle (diet/ exercise) might partially prevent or redress the decline of androgen levels with aging (11-13).

\section{ADMINISTRATION OF TESTOSTERONE TO MEN WITH DIABETES MELLITUS}

Testosterone substitution in hypogonadal men improves insulin sensitivity. Furthermore, testosterone reduces insulin levels and insulin resistance in men with obesity. A study in hypogonadal men with type 2 diabetes has shown that testosterone replacement also improves glycemic control, although this study was non-blinded (14). By contrast, two studies replacing testosterone in men with type 2 diabetes and hypogonadism found little or no effect on glycemic control $(15,16)$, but a more recent study analyzing the effects of testosterone administration to 24 hypogonadal men ( 10 treated with insulin) older than 30 years old with type 2 diabetes found that testosterone replacement therapy reduced insulin resistance (as measured by homeostatic model index) and improved glycemic control in hypogonadal men with type 2 diabetes (17). A recent study in newly diagnosed men showed convincingly that addition of testosterone to a regimen of diet and exercise produced significantly better results than diet and exercise on glycemic control and reversal of the metabolic syndrome (13).

So, while the evidence for powerful effects of normalization of circulating levels of testosterone on glucose homeostasis is limited so far, there are studies to prove that administration of testosterone may provide favorable effects on glycemic control and on the metabolic sequels of diabetes mellitus.

\section{EFFECTS OF TESTOSTERONE ADMINISTRATION ON FAT TISSUE AND LIPID METABOLISM}

Sex steroid hormones are involved in the metabolism, accumulation and distribution of adipose tissues. It is now known that there are estrogen receptors, progesterone receptors and androgen receptors in adipose tissues, so their actions could be direct. Sex steroid hormones carry out their function in adipose tissues by both genomic and nongenomic mechanisms. Activation of the cAMP cascade by sex steroid hormones would activate hormone-sensitive lipase leading to lipolysis in adipose tissues. In the phosphoinositide cas- 
cade, diacylglycerol and inositol 1,4,5-trisphosphate are formed as second messengers ultimately causing the activation of protein kinase $\mathrm{C}$. Their activation appears to be involved in the control of preadipocyte proliferation and differentiation. The role of testosterone in regulating lineage determination in mesenchymal pluripotent cells by promoting their commitment to the myogenic lineage and inhibiting their differentiation into the adipogenic lineage through an androgen receptor-mediated pathway has been convincingly demonstrated. In a clinical study, it could be shown that testosterone inhibits triglyceride uptake and lipoprotein lipase activity and causes a more rapid turnover of triglycerides in the subcutaneous abdominal adipose tissue and less so in femoral fat and, maybe, mobilizes lipids from the visceral fat depot. In this study, testosterone administration restoring testosterone levels to midnormal values with a duration of 8-9 months leads to a decrease of the visceral fat mass, a decrease of fasting glucose and lipid levels and an improvement of insulin sensitivity; in addition, a decrease in diastolic blood pressure was observed.

A recent meta-analysis of randomized controlled trials evaluating the effects of testosterone $(\mathrm{T})$ administration to middle-aged and ageing men on body composition showed a reduction of $1.6 \mathrm{~kg}$ (CI: 2.5-0.6) of total body fat, corresponding to $-6.2 \%$ (CI: 9.2-3.3) variation of initial body fat, an increase in fat free mass of $1.6 \mathrm{~kg}$ (CI: 0.6-2.6), corresponding to $+2.7 \%$ (CI: 1.1 $4.4)$ increase over baseline and no change in body weight. Testosterone also reduced total cholesterol by 0.23 $\mathrm{mmol} / \mathrm{L}$ (CI: -0.37 to -0.10 ), especially in men with lower baseline $\mathrm{T}$ concentrations, with no change in low density lipoprotein (LDL)-cholesterol. A significant reduction of high density lipoprotein (HDL)-cholesterol was found only in studies with higher mean T-values at baseline or when androgens were non-aromatizable $(-0.085 \mathrm{mmol} / \mathrm{L}, \mathrm{CI}:-0.017$ to -0.003$)(18)$.

\section{TESTOSTERONE AND INFLAMMATORY STATE}

Pro-inflammatory cytokines such as TNF $\alpha$, IL- 1 and IL-6 are involved in atherogenesis. By contrast, IL10 and adiponectin are atheroprotective. Testosterone exerts an immunosuppressive effect on the immune system. Inflammation, infection and trauma reduce testosterone levels as a result of the suppressive action of inflammatory cytokines on the hypothalamic-pituitarytestis axis. Testosterone also directly inhibits cytokine production from lymphocytes.
Administration of testosterone to hypogonadal men with coronary heart disease reduced serum TNF $\alpha$ and IL-1 $\beta$, but not IL6 levels and raised levels of IL-10. In testosterone deficient men suffering from diabetes type 2 , baseline testosterone levels inversely correlate with IL-6 and CRP levels. This is also the case in nondiabetic men. In the study of diabetic men, testosterone replacement had no effect on TNF $\alpha$, IL-6 or CRP levels. Testosterone did reduce serum leptin and adiponectin levels. This effect may potentially be mediated via reduction in adipose tissue. Similar effects of testosterone replacement in these men have been shown in non-diabetic hypogonadal men. In a study of hypogonadal men of whom the majority had coronary heart disease testosterone therapy suppressed serum TNF $\alpha$ and IL- $1 \beta$ and increased the anti-atherogenic cytokine interleukin-10 (19).

Adiponectin is atheroprotective and the drop in the level of this cytokine is opposite to the effects of testosterone on other components of the atherogenic cytokine profile. This was a short-term study and may reflect initial reduction in fat mass. Longer-term studies are needed to determine whether adiponectin levels remain low or rise. Clearly, there are interesting effects of testosterone on inflammatory and coagulation states that require further investigation.

\section{TESTOSTERONE AND LIPIDS}

In a large epidemiological study (The Telecom Study), there appeared to be an association of testosterone and cardiovascular risk factors in healthy, non-diseased adult men. Serum triglycerides, total cholesterol, LDL-cholesterol, apolipoprotein B, fasting and 2-hour plasma insulin were higher and values of serum HDLcholesterol were lower in men with lower serum testosterone levels.

The fact that testosterone is a significant factor in this difference in risk profile is demonstrated by observations in men receiving androgen ablation treatment for prostate carcinoma, resulting in a rather acute and profound decline of serum testosterone. In these men, there is an increase of serum cholesterol, LDL-cholesterol and triglycerides and a decrease in HDL-cholesterol (20). The role of testosterone is further corroborated by the favorable effects of administration of testosterone on lipid profiles in a study of men with newly diagnosed diabetes mellitus and the metabolic syndrome (13). These effects are persistent over time as evident from a 
study of men receiving parenteral testosterone undecanoate for up to 9.5 years $(21)$.

\section{THE ASSOCIATION BETWEEN PLASMA LEVELS OF TESTOSTERONE AND BLOOD PRESSURE}

There is evidence from epidemiological studies on metabolic syndrome that there is an inverse relationship between circulating levels of testosterone and blood pressure. Lower levels of testosterone in men are associated with higher blood pressure, left ventricular mass, and left ventricular hypertrophy for review (22). Part of the explanation may be the stiffening of large arteries, as observed in men who receive androgen ablation treatment with GnRH-agonists for prostate cancer and who experience a drastic decrease of circulating testosterone levels (23). The first study to demonstrate a favorable effect of testosterone treatment on blood pressure in abdominally obese men was published by Marin and cols. (24). Another study investigating the effects of testosterone treatment for men with osteoporosis found also a beneficial effect on blood pressure levels. In a study of 122 men receiving treatment with parenteral testosterone undecanoate over 15 months, both systolic and diastolic blood pressure decreased (25). The maximum effect was attained after nine months of testosterone administration. A single-blind randomized study of testosterone administration to men with metabolic syndrome and recent onset of diabetes mellitus established also beneficial effects of testosterone on blood pressure over and above the effects of diet and exercise (13). These effects are persistent as demonstrated in a study of men receiving testosterone treatment up to 9.5 years $(21)$.

\section{COAGULATION}

Low levels of testosterone are associated with a hypercoagulable state. In men with low levels of testosterone, levels of plasminogen activator inhibitor type 1 (PAI-1), Factor VII and fibrinogen all are negatively correlated with testosterone levels whereas tissue plasminogen activator ( $\mathrm{tPA})$ is positively correlated. In this manner, a hypogonadal state carries a higher risk of hypercoagulability. No studies have been performed in men with diabetes so far. A side effect of testosterone administration may be an elevation of the hematocrit, but this is dose-dependent and with more modern modes of testosterone administration occurs infrequently.

\section{CONCLUSIONS}

In recent times, the understanding and thinking about the (patho)physiological functions of testosterone have undergone a revolutionary development. While the significance of testosterone for male reproductive/sexual functioning has been obvious to most physicians, they now need to familiarize themselves with the insight that testosterone is a key-player in glucose homeostasis, lipid metabolism, and cardiovascular pathology (26).

Earlier, it was firmly believed that testosterone had no essential role to play in male physiology other than on sexual and reproductive functioning. Physicians will have to change their mind-set and accept that testosterone is a vital hormone for men's health. Recent epidemiological studies have found that low testosterone levels constitute a predictor of mortality in elderly men (27-31).

Obviously, epidemiological studies cannot unravel cause-relationships, but the evidence that the decline in testosterone levels with aging is accounted for rather by (age-related) disease than the calendar age of men is convincing. Intervention studies provide potential answers to the causality of the relationship. It is no exaggeration to say that in modern medicine and endocrinology testosterone is no longer a marginal hormone. Neither is it a life-style hormone for those men seeking eternal youth. Its deficiency leads to a serious deterioration of the health of men expressing itself in the metabolic syndrome and its sequelae: diabetes mellitus type 2 and atherosclerotic disease accelerating morbidity and mortality (32). Intervention studies in men with diabetes mellitus are limited in number, but hold promise. Normalization of testosterone levels may improve insulin sensitivity and have favorable effects on visceral adiposity and lipid profiles. The long held belief that testosterone has adverse effects on cardiovascular disease, explaining the male preponderance in cardiovascular morbidity and mortality appears not to be supported by rigorous scientific testing. Neither is the fear that testosterone administration to elderly men increases the risk of prostate malignancies justified. It only requires prudence in clinical management.

Disclosure: the author is an employee of Bayer-Schering Pharma, the manufacturer of testosterone products. In the opinion of the author, the views expressed in this paper are unbiased and impartial with regard to recommendations on the administration of testosterone. No other potential conflict of interest relevant to this article was reported.

\section{REFERENCES}

1. Saad F, Gooren L. The role of testosterone in the metabolic syndrome: a review. J Steroid Biochem Mol Biol. 2009;114(1-2):40-3. 
2. Stanworth RD, Jones TH. Testosterone in obesity, metabolic syndrome and type 2 diabetes. Front Horm Res. 2009;37:74-90.

3. Stanworth RD, Kapoor D, Channer KS, JonesTH. Statin therapy is associated with lower total but not bioavailable or free testosterone in men with type 2 diabetes. Diabetes Care. 2009;32(4):541-6.

4. Ding EL, Song Y, Malik VS, Liu S. Sex differences of endogenous sex hormones and risk of type 2 diabetes: a systematic review and meta-analysis. JAMA. 2006;295(11):1288-99.

5. Traish AM, Saad F, Guay A. The dark side of testosterone deficiency: II. Type 2 diabetes and insulin resistance. J Androl. 2009;30(1):23-32.

6. Chandel A, Dhindsa S, Topiwala S, Chaudhuri A, Dandona P.Testosterone concentration in young patients with diabetes. Diabetes Care. 2008;31(10):2013-7.

7. Stanworth RD, Kapoor D, Channer KS, Jones TH. Androgen receptor CAG repeat polymorphism is associated with serum testosterone levels, obesity and serum leptin in men with type 2 diabetes. Eur J Endocrinol. 2008;159(6):739-46.

8. Pitteloud N, Hardin M, Dwyer AA, Valassi E, Yialamas M, Elahi D, et al. Increasing insulin resistance is associated with a decrease in Leydig cell testosterone secretion in men. J Clin Endocrinol Metab. 2005;90(5):2636-41.

9. Castro-Fernandez C, Olivares A, Soderlund D, Lopez-Alvarenga JC, Zambrano E, Veldhuis JD, et al. A preponderance of circulating basic isoforms is associated with decreased plasma half-life and biological to immunological ratio of gonadotropin-releasing hormone-releasable luteinizing hormone in obese men. J Clin Endocrinol Metab. 2000;85(12):4603-10.

10. Travison TG, Araujo AB, Kupelian V, O'Donnell AB, McKinlay JB. The relative contributions of aging, health, and lifestyle factors to serum testosterone decline in men. J Clin Endocrinol Metab. 2007;92(2):549-55.

11. Cicero AF, Derosa G, Bove M, Di Gregori V, Gaddi AV, Borghi C. Effect of a sequential training programme on inflammatory, prothrombotic and vascular remodelling biomarkers in hypertensive overweight patients with or without metabolic syndrome. Eur J Cardiovasc Prev Rehabil. 2009. [Epub ahead of print]

12. Esposito K, Marfella R, Ciotola M, Di Palo C, Giugliano F, Giugliano $G$, et al. Effect of a Mediterranean-style diet on endothelial dysfunction and markers of vascular inflammation in the metabolic syndrome: a randomized trial. JAMA 2004;292(12):1440-6.

13. Heufelder AE, Saad F, Bunck MC, Gooren LJ. 52-Week treatment with diet and exercise plus transdermal testosterone reverses the metabolic syndrome and improves glycaemic control in men with newly diagnosed type 2 diabetes and subnormal plasma testosterone. J Androl. 2009. [Epub ahead of print].

14. Boyanov MA, Boneva Z, Christov VG. Testosterone supplementation in men with type 2 diabetes, visceral obesity and partial androgen deficiency. Aging Male. 2003;6(1):1-7.

15. Corrales JJ, Almeida M, Burgo R, Mories MT, Miralles JM, Orfao A. Androgen-replacement therapy depresses the ex vivo production of inflammatory cytokines by circulating antigen-presenting cells in aging type-2 diabetic men with partial androgen deficiency. $J$ Endocrinol. 2006;189(3):595-604.

16. Lee $\mathrm{CH}$, Kuo SW, Hung YJ, Hsieh $\mathrm{CH}$, He CT, Yang TC, et al. The effect of testosterone supplement on insulin sensitivity, glucose effectiveness, and acute insulin response after glucose load in male type 2 diabetics. Endocr Res. 2005;31(2):139-48.
17. Kapoor D, Goodwin E, Channer KS, JonesTH. Testosterone replacement therapy improves insulin resistance, glycaemic control, visceral adiposity and hypercholesterolaemia in hypogonadal men with type 2 diabetes. Eur J Endocrinol. 2006;154(6):899-906.

18. Isidori AM, Giannetta E, Greco EA, Gianfrilli D, Bonifacio V, Isidori $A$, et al. Effects of testosterone on body composition, bone metabolism and serum lipid profile in middle-aged men: a metaanalysis. Clin Endocrinol (Oxf). 2005;63(3):280-93.

19. Kapoor D, Clarke S, Stanworth R, Channer KS, Jones TH. The effect of testosterone replacement therapy on adipocytokines and $\mathrm{C}$-reactive protein in hypogonadal men with type 2 diabetes. Eur J Endocrinol. 2007;156(5):595-602.

20. Haidar A, Yassin A, Saad F, Shabsigh R. Effects of androgen deprivation on glycaemic control and on cardiovascular biochemical risk factors in men with advanced prostate cancer with diabetes. Aging Male. 2007;10(4):189-96.

21. Saad F, Kamischke A, Yassin A, Zitzmann M, Schubert M, Jockenhel $F$, et al. More than eight years' hands-on experience with the novel long-acting parenteral testosterone undecanoate. Asian $\mathrm{J}$ Androl. 2007;9(3):291-7.

22. Jones TH, Saad F. The effects of testosterone on risk factors for, and the mediators of, the atherosclerotic process. Atherosclerosis. 2009. [Epub ahead of print]

23. Basaria S, Muller DC, Carducci MA, Egan J, Dobs AS. Hyperglycemia and insulin resistance in men with prostate carcinoma who receive androgen-deprivation therapy. Cancer. 2006;106(3):581-8.

24. Marin P, Holmang S, Gustafsson C, Jonsson L, Kvist H, Elander A, et al. Androgen treatment of abdominally obese men. Obes Res. 1993;1(4):245-51.

25. Yassin AA, Saad F. Improvement of sexual function in men with late-onset hypogonadism treated with testosterone only. J Sex Med. 2007;4(2):497-501.

26. Corona G, Mannucci E, Forti G, Maggi M. Following the common association between testosterone deficiency and diabetes mellitus, can testosterone be regarded as a new therapy for diabetes? Int J Androl. 2009;32(5):431-41.

27. Shores MM, Moceri VM, Gruenewald DA, Brodkin KI, Matsumoto AM, Kivlahan DR. Low testosterone is associated with decreased function and increased mortality risk: a preliminary study of men in a geriatric rehabilitation unit. J Am Geriatr Soc. 2004;52(12):2077-81.

28. Shores MM, Matsumoto AM, Sloan KL, Kivlahan DR. Low serum testosterone and mortality in male veterans. Arch Intern Med. 2006;166(15):1660-5.

29. Khaw KT, Dowsett M, Folkerd E, Bingham S, Wareham N, Luben R, et al. Endogenous testosterone and mortality due to all causes, cardiovascular disease, and cancer in men: European prospective investigation into cancer in Norfolk (EPIC-Norfolk) Prospective Population Study. Circulation. 2007;116(23):2694-701.

30. Laughlin GA, Barrett-Connor E, Bergstrom J. Low serum testosterone and mortality in older men. J Clin Endocrinol Metab. 2008;93(1):68-75.

31. Maggio M, Lauretani F, Ceda GP, Bandinelli S, Ling SM, Metter EJ, et al. Relationship between low levels of anabolic hormones and 6-year mortality in older men: the aging in the Chianti Area (InCHIANTI) study. Arch Intern Med. 2007;167(20):2249-54.

32. Traish AM, Guay A, Feeley R, Saad F.The dark side of testosterone deficiency: I. Metabolic syndrome and erectile dysfunction. J Androl. 2009;30(1):10-22. 